\title{
NEW APPROACH TO PATENCY AND FLOW ASSESSMENT AFTER LEFT INTERNAL THORACIC ARTERY HYPOPERFUSION SYNDROME WITH ADDITIONAL SAPHENOUS VEIN GRAFT TO THE LEFT ANTERIOR DESCENDING ARTERY WITH PHASE-CONTRAST MAGNETIC RESONANCE ANGIOGRAPHY
}

Gregor Zünd, $\mathrm{MD}^{\mathrm{a}}$

Markus Hauser, MD ${ }^{\mathrm{b}}$

Paul Vogt, $\mathrm{MD}^{\mathrm{a}}$

Clarence P. Davis, MD $^{\mathrm{b}}$

Mario Lachat, $\mathrm{MD}^{\mathrm{a}}$

Andreas Künzli, MD ${ }^{\mathrm{a}}$

Michele Genoni, $\mathrm{MD}^{\mathrm{a}}$

Marko Turina, $\mathrm{MD}^{\mathrm{a}}$
Objective: Perioperative and early postoperative flow reduction of a left internal thoracic artery conduit is a rare complication of myocardial revascularization and may lead to the potentially fatal left internal thoracic artery hypoperfusion syndrome. It has been advocated that an additional vein graft be placed to the distal left anterior descending artery to provide sufficient myocardial perfusion. Some evidence exists, however, that this high-flow vein might lead to competing or even backward flow through the internal thoracic artery. Methods: In the past 2 years, 21 patients received an additional vein graft to the distal left anterior descending artery for left internal thoracic artery hypoperfusion syndrome. Nineteen of these patients were available for magnetic resonance imaging. Early ( $<6$ months) and late (>12 months) postoperative flow measurements, both in the left internal thoracic artery and in the saphenous vein grafts, were performed by means of conventional and a segmented k-space phase-contrast magnetic resonance angiography technique. Results: Early magnetic resonance examinations indicated that all conduits had adapted to the coronary flow type with predominant diastolic perfusion. Patency rate both at the early and at the late study was $100 \%$. No concurrent flow, flow reversal, or steal phenomena were observed. Mean flow rates were $49.2 \mathrm{ml} / \mathrm{min}$ for the left internal thoracic artery and $72.6 \mathrm{ml} / \mathrm{min}$ for the saphenous vein graft. Conclusion: On the basis of the flow data obtained with magnetic resonance angiography, the use of an additional saphenous vein graft as the treatment of choice in left internal thoracic artery hypoperfusion syndrome does not lead to occlusion of the artery. Conduit flow adaptation to the diastolic predominance occurs in the first 6 months after operation. (J Thorac Cardiovasc Surg 1997;114:428-33)
T he internal thoracic artery (LITA) has become the conduit of choice for myocardial revascularization, since it has been proved that early mortality and morbidity are low. ${ }^{1-3}$ The long-term patency rates of LITA grafts are superior to those of saphenous vein bypass grafts, and late atherosclerotic lesions rarely

From the Clinic for Cardio-vascular Surgery, ${ }^{a}$ Department of Medical Radiology, Institute of Diagnostic Radiology, and MR Center, ${ }^{b}$ Zurich University Hospital, Zurich, Switzerland.

Received for publication Jan. 21, 1997; revisions requested Feb. 19, 1997; revisions received May 13, 1997; accepted for publication May 14, 1997.

Address for reprints: Gregor Zünd, MD, Clinic for Cardiovascular Surgery, University Hospital Zurich, Raemistrasse 100, CH-8091 Zurich, Switzerland.

Copyright $\mathbb{0} 1997$ by Mosby-Year Book, Inc.

$0022-5223 / 97 \$ 5.00+0 \quad \mathbf{1 2 / 1 / 8 3 2 3 5}$ occur in these vessels. ${ }^{4-6}$ Perioperative or early postoperative malperfusion of the LITA is a rare complication of coronary artery bypass grafting and may lead to the potentially fatal LITA hypoperfusion syndrome, which is caused by an acute imbalance between myocardial demand and nutritional support through the LITA. ${ }^{7-10}$ The cause of this syndrome may be inadequate flow caused by spasm, steal phenomena, small size of the LITA, and caliper mismatch between the LITA and recipient coronary vessel in the presence of a technically satisfactory anastomosis or by large myocardial flow demand in a severely hypertrophied ventricle. Careless preparation of the LITA is especially likely to lead to arterial spasm. It has been advocated that an additional vein graft be placed to the distal left anterior descending artery (LAD) to provide sufficient myocardial perfusion and to prevent a myocardial 
infarction. ${ }^{11}$ Some evidence exists, however, that this high-flow vein might lead to concurrent or even backward LITA flow. ${ }^{12-15}$ This study was undertaken to determine early and late postoperative flow rates in the LITA and in the additional saphenous vein grafts to the LAD.

\section{Patients and methods}

In a series of 1163 consecutive isolated myocardial revascularizations performed between 1994 and 1995, we identified 21 patients $(1.8 \%)$ receiving an additional vein graft to the distal LAD for LITA hypoperfusion syndrome. LITA grafts are used in $92 \%$ of our patients. The standard way of preparing LITA grafts included wide opening of the left pleural cavity and mobilization of the LITA within a pedicle of $2 \mathrm{~cm}$ of the endothoracic fascia by low-powered electrocautery. The pedicle was immersed in a $1 \%$ papaverine solution and not touched further until implantation. Cardiopulmonary bypass was conducted under moderate hypothermia, and revascularization was performed during a single period of cardioplegic arrest. LITA anastomoses were performed only when flow through the LITA was found to be adequate. The anastomoses were sutured with 7-0 polypropylene and tested with a 1.5 to $2 \mathrm{~mm}$ probe. The 21 patients in this series had perioperative or early postoperative symptoms (within in first postoperative 24 hours) such as hemodynamic collapse, acute increase in pulmonary pressure, electrocardiographic changes compatible with anterolateral ischemia, and decreased contractility in the region supplied. In these cases an additional saphenous vein graft was interposed between the ascending aorta and the distal LAD during a short period of ventricular fibrillation. During revision, an arteriotomy was made in the LAD distal to the site of the LITA anastomosis, and a $1.5 \mathrm{~mm}$ probe was advanced retrogradely into the proximal coronary vessel and across the anastomosis into the LITA. All patients survived this additional procedure.

Nineteen of the 21 patients (male/female $=12 / 7$, mean age 64.3 years) were available for magnetic resonance (MR) imaging. In two patients the examination could not be performed because of implanted pacemakers. Early $(<6$ months) and late ( $>12$ months) postoperative flow measurements both in the LITA and in the saphenous vein grafts were performed with a 1.5 -tesla MR imager (Signa Advantage; GE Medical Systems, Milwaukee, Wis.). Fat-suppressed segmented k-space breath-held 5 $\mathrm{mm}$ thick slices were acquired in the axial and oblique sagittal planes to identify the proximal vein graft and the LITA conduit. Subsequently, both cine phase-contrast imaging and segmented k-space cine phase-contrast imaging were acquired perpendicular to the conduit to be studied (Fig. 1, $a$ to $c$ ). The imaging parameters for cine phase-contrast imaging were as follows: field-of-view 24 $\mathrm{cm}$; image matrix $256 \times 256$, rendering an in-plane resolution of $0.9 \times 0.9 \mathrm{~mm}$; flip angle 45 degrees; 2 NEX; TR/TE 32/8 msec; slice $5 \mathrm{~mm}$; 16 phases.* The imaging

${ }^{*} \mathrm{NEX}=$ Number of excitations; $\mathrm{TR}=$ relaxation time; $\mathrm{TE}=$ excitation time.
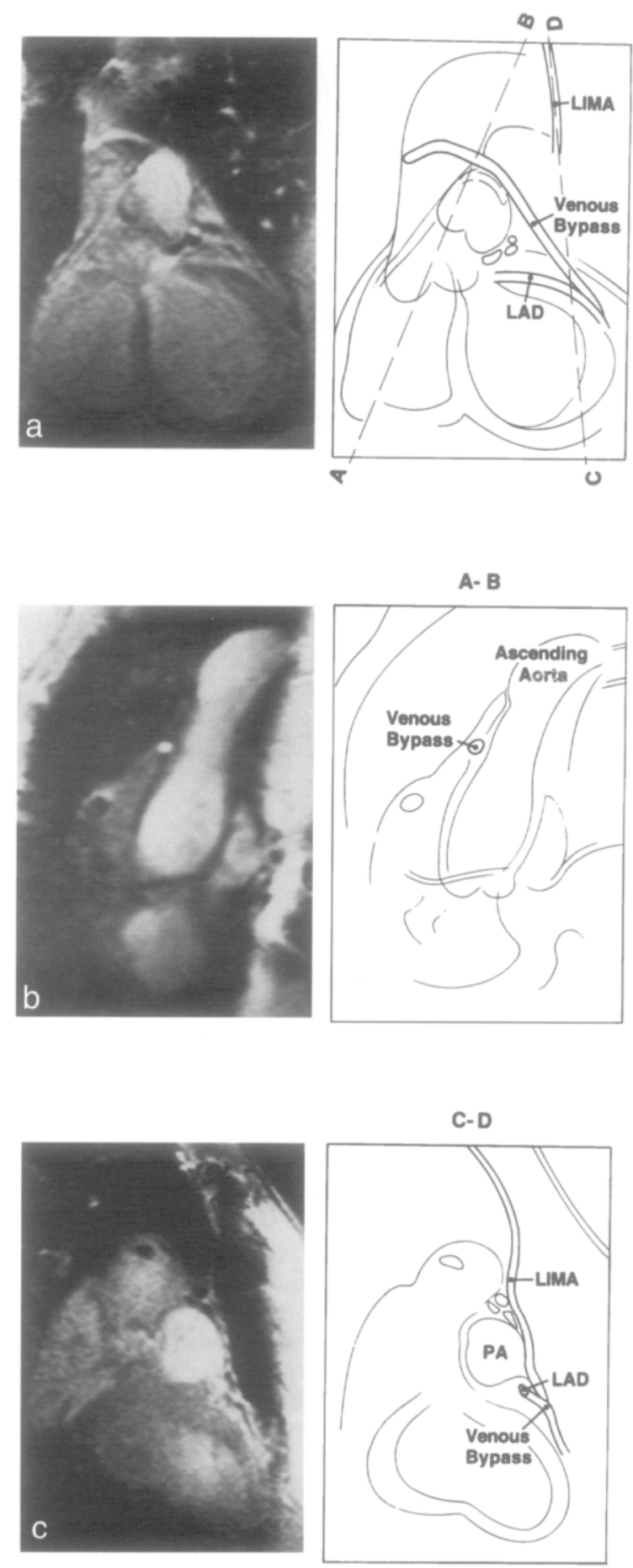

Fig. 1. Fast-gradient echo MR images and corresponding diagrams describing the technique used for bypass localization. a, Coronal localizer sequence with orthogonal visualization of the LITA (LIMA) and venous graft. b, Oblique sagittal plane corresponding to line $A-B$ with cross section through venous graft. c, Oblique sagittal plane corresponding to line $C-D$ with visualization of the LITA-LAD anastomosis. $P A$, Pulmonary artery. 


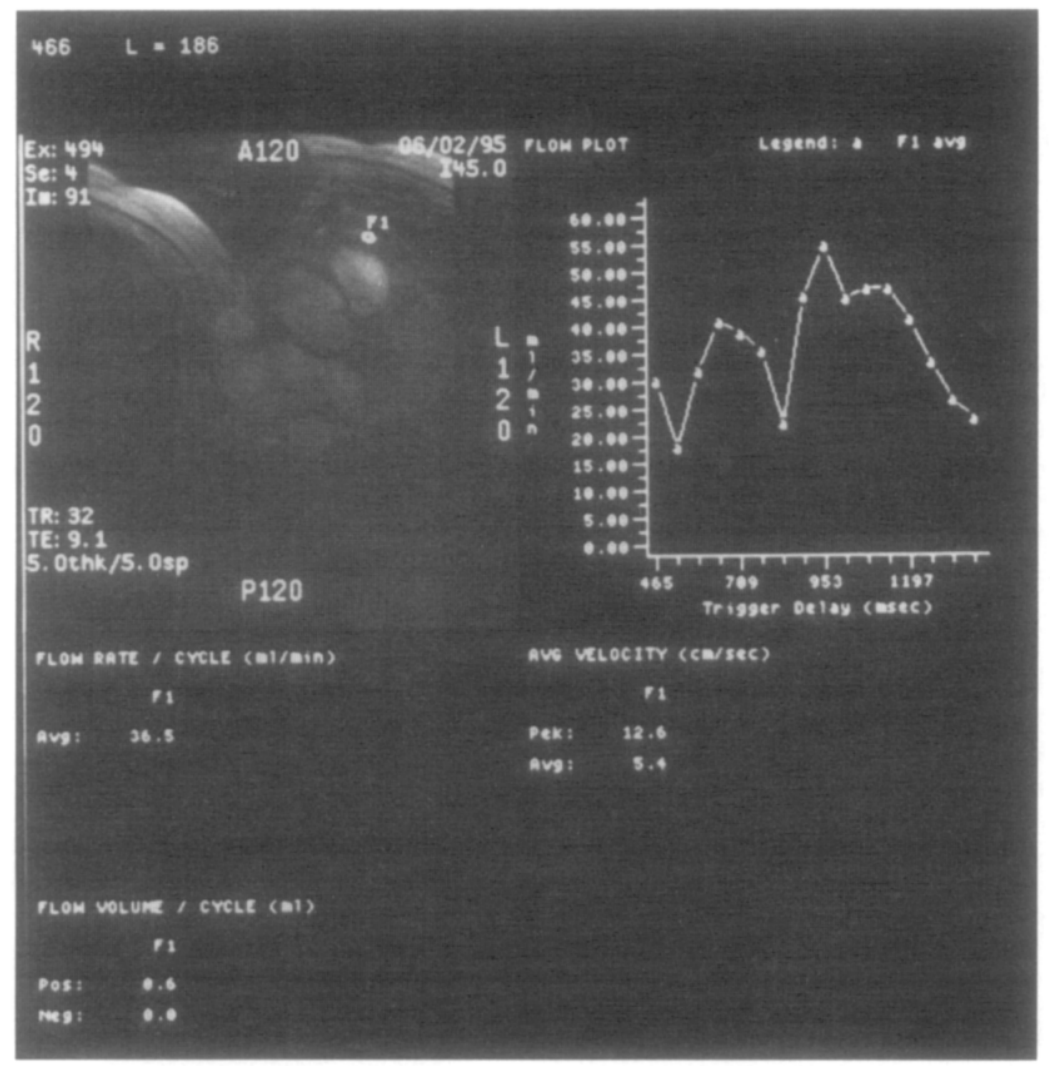

Fig. 2. MR phase-contrast flow measurement in a venous graft. Upper left, Gradient echo image with indicated region of interest (F1). Upper right, Graphic depiction of flow rate ( $\mathrm{ml} / \mathrm{min}$ ) during an RR interval. The calculated mean flow rate in this example was $36.5 \mathrm{ml} / \mathrm{min}$, and mean systolic peak velocity was $12.6 \mathrm{~cm} / \mathrm{sec}$.

parameters for segmented k-space phase-contrast imaging were as follows: field-of-view $22 \times 11 \mathrm{~cm}$; image matrix $256 \times 96$, rendering an in-plane resolution of $0.8 \times 1.15$ mm; flip angle 25 degrees; TR/TE 19.8/11.6 msec. The velocity encoding value was $120 \mathrm{~cm} / \mathrm{sec}$. Each cardiac cycle provided a temporal resolution of approximately $87 \mathrm{msec}$ using $4 \mathrm{k}$-lines per cycle with subsequent 7 to 14 phase and magnitude images per heartbeat. Flow rates were measured by means of standard software equipment with an operator-defined region of interest method (mean region of interest $19 \mathrm{~mm}^{2}$, Fig. 2).

\section{Results}

Preoperative selective angiography of both ITAs is routinely performed at the end of every coronary angiography at our institution. No anomalies of the LITA or significant branches were observed in our patient group. In addition, no evident correlation between preoperative angiographic findings and development of LITA malperfusion could be observed. Visual assessment of the internal thoracic artery (ITA) was done in terms of adequacy of pulse, size, injury, and arteriosclerosis. The caliper of the graft was estimated to be adequate ( 2 to 4 $\mathrm{mm}$ ) in all patients. Strong evidence for ITA spasm was observed in four patients. In these patients, an intraoperative continuous low dose of nifedipine (5 to $10 \mu \mathrm{g} / \mathrm{min}$ ) was administered systemically. Early postoperative ( $<8$ weeks) coronary angiography was performed in all 21 patients, showing widely patent LITA grafts and a patent additional saphenous vein graft to the distal LAD. At the time of the MR imaging all patients were in New York Heart Association class I or II.

In all patients, the venous and arterial grafts could be identified by MR imaging and flow could be measured as well. Early MR studies ( $<6$ months after the operation) indicated that all conduits had adapted to the coronary flow type with predominant diastolic perfusion. Patency rate both at the early and at the late study $(>12$ months after the operation) was $100 \%$. No concurrent flow, flow reversal, or steal phenomena 


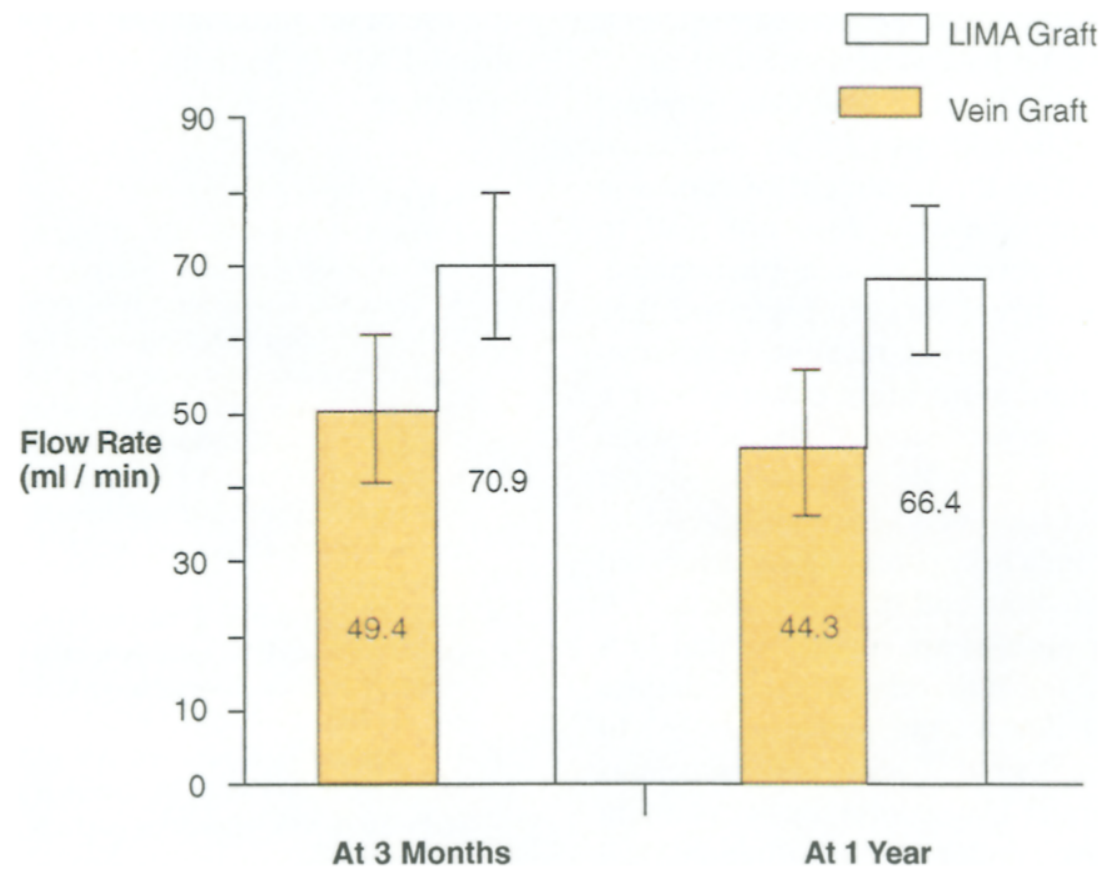

Fig. 3. Comparison of early and late postoperative flow rates in arterial and venous coronary grafts.

were observed. Mean flow rates were $49.2 \mathrm{ml} / \mathrm{min}$ for the saphenous vein graft and $72.6 \mathrm{ml} / \mathrm{min}$ for the LITA (at 3 months $49.4 \mathrm{ml} / \mathrm{min}$ and at 1 year $44.3 \mathrm{ml} / \mathrm{min}$ for the saphenous vein graft; at 3 months $70.9 \mathrm{ml} / \mathrm{min}$ and at 1 year $66.4 \mathrm{ml} / \mathrm{min}$ for the LITA) (Fig. 3).

\section{Discussion}

Surgical revascularization of the myocardium has evolved into an extremely safe, predictable, and life-prolonging procedure. ${ }^{16}$ The ITA has been shown to be the conduit with the greatest longevity among those currently available for coronary artery bypass grafting. ${ }^{1-3}$ Unlike saphenous vein grafts, failures of LITA grafts are seldom due to atherosclerotic changes or intimal graft hyperplasia but rather are thought to be due to technical problems with the graft. Furthermore, immediate blood flow through this arterial graft is generally less than through a saphenous vein graft. The LITA malperfusion syndrome is the clinical entity reported to result from inadequate flow through this arterial graft. $^{7}$

This study was designed to examine the patency and flow rates in LITA grafts and additional saphenous vein grafts when both vessels were anastomosed to the same coronary artery, the LAD. Some evidence has been offered that the additional high- flow vein grafted distal to the LITA might lead to concurrent flow reversal or even backward LITA flow. ${ }^{14,15}$

ITA malperfusion syndrome is caused by an acute imbalance between myocardial demand and nutritional support through the ITA. The mechanism of this syndrome during and after coronary surgery has not yet been fully elucidated, but this syndrome requires early diagnosis and immediate aggressive treatment, and this may be crucial for the survival of the patient. The cause may be inadequate flow resulting from spasm, steal phenomena, small size of the LITA, and caliper mismatch between the LITA and recipient coronary vessel in the presence of a technically satisfactory anastomosis. ${ }^{17}$ An additional saphenous vein graft to the distal LAD, grafted distal to the LITA implantation site, has been recognized as an effective approach to prevent further ischemia. In our series, postoperative coronary angiography demonstrated patency of both the arterial and saphenous vein graft in all patients and no technical error could be proved. However, the flow in the LITA graft is of special interest. Flow in the saphenous vein graft is higher than in the ITA, and a concurrent or even backward LITA flow may be reasonable. The long-term patency rate of the LITA grafts is superior to that of saphenous vein grafts, and late atherosclerotic lesions rarely occur in these 
vessels. It is evident that the LITA graft stays patent, and concurrent or even backward flow may lead to graft occlusion. On the basis of flow data obtained with MR angiography, the use of an additional saphenous vein graft as the treatment of choice in LITA hypoperfusion syndrome does not lead to concurrent flow, flow reversal, or steal phenomena. In the event of concurrent or even backward flow late in the postoperative period, resulting in narrowing and ultimate failure of the graft, a thoracoscopic clipping or a catheter occlusion of the additional saphenous vein graft may be discussed. Recent results from animal experiments have indicated that competitive flow from a fully patent native artery did not stop LITA graft flow and does not cause ITA shriveling. ${ }^{12,18}$ The authors are suggesting that ITA grafts are dynamic and may remain patent despite significant residual flow in the native vessel. ${ }^{18}$ In addition, Kitamura, ${ }^{19}$ Feld, ${ }^{20}$ and their associates report that ITA grafts may continuously maintain anatomic patency even under no-flow situations, just like nonfunctional collateral vessels, and may function properly later as a graft when the native coronary flow decreases. Others ${ }^{21}$ are reporting cases in which an ITA graft was found to be nonfunctional in the early postoperative period, with the possibility of competitive flow as the cause of the temporary closure of the graft. In contrast, other authors ${ }^{13}$ believe that competitive flow does not cause vessel or graft occlusion if the anastomosis is technically satisfactory. Flemma and coworkers ${ }^{22}$ reported a clinical experiment in which they inserted an LITA graft into the hood of a coronary artery saphenous vein bypass graft, with continued patency of both conduits.

In addition, if proximal subclavian artery disease coexists or develops in a patient who had myocardial revascularization with an in situ LITA, myocardial ischemia can occur. For this reason, a careful evaluation and postoperative follow-up of the subclavian arteries, even by simple comparison of bilateral arm blood pressure, should help to reduce the prevalence of this syndrome. In these cases carotidsubclavian bypass grafting appears to be the treatment of choice. ${ }^{23}$

The use of an additional saphenous vein graft as the treatment of choice in LITA hypoperfusion syndrome does not lead to LITA occlusion or to concurrent flow, flow reversal, or steal phenomena. Conduit flow adaptation to the diastolic predominance occurs within the first 6 months after the operation. On the basis of our data, we recommend the use of an additional saphenous vein graft to the distal LAD in patients with LITA hypoperfusion syndrome.

\section{REFERENCES}

1. Barner HB, Standeven JW, Reese J. Twelve-year experience with internal mammary artery for coronary artery bypass. J Thorac Cardiovasc Surg 1985;90:668-75.

2. Lytle BW, Loop FD, Cosgrove DM, Ratliff NB, Easley K, Taylor PC. Long-term (5 to 12 years) serial studies of internal mammary artery and saphenous vein coronary bypass grafts. J Thorac Cardiovasc Surg 1985;89:248-58.

3. Cameron A, Davis KP, Green G, Schaff HV. Coronary bypass surgery with internal-thoracic artery grafts: effects on survival over a 15-year period. N Engl J Med 1996;25;334: 216-9.

4. Loop FD, Lytle BW, Cosgrove DM, Stewart RW, Goormastic M, Williams GW, et al. Influence of the internal mammary-artery graft on 10-year survival and other cardiac events. N Engl J Med 1986;314:1-6.

5. Huddleston CB, Stoney WS, Alford WC, Burrus GR, Glassford DM, Lea JW, et al. Internal mammary artery graft: technical factors influencing patency. Ann Thorac Surg 1986; 42:543-9.

6. Olearchyk AS, Magovern GJ. Internal mammary artery grafting. J Thorac Cardiovasc Surg 1986;92:1082-7.

7. Vajtai P, Raviachandran PS, Fessler CL, Floten HS, Ahmad A, Gately HL, et al. Inadequate internal mammary artery graft as a cause of postoperative ischemia: incidence, diagnosis and management. Eur J Cardiothorac Surg 1992;6: 603-8.

8. Sarabu MR, McClung JA, Fass A, Reed GE. Early postoperative spasm in left internal mammary artery bypass grafts. Ann Thorac Surg 1987;44:199-200.

9. Von Segesser L, Simonet F, Meier B, Finci L, Faidutti B. Inadequate flow after internal mammary coronary artery anastomosis. Thorac Cardiovasc Surg 1987;35:352-4.

10. Loop FD, Thomas JD. Hypoperfusion after arterial bypass grafting. Ann Thorac Surg 1993;56:812-3.

11. Jones EL, Lattout OM, Weintraub WS. Catastrophic consequences of internal mammary artery hypoperfusion. J Thorac Cardiovasc Surg 1989;98:902-7.

12. Spence PA, Lust RM, Zeri RS, Jolly SR, Mehta PM, Otaki $\mathrm{M}$, et al. Competitive flow from a fully patent coronary artery does not limit acute mammary graft flow. Ann Thorac Surg 1992;54:21-6.

13. Suma H. Internal thoracic artery and competitive flow [letter]. J Thorac Cardiovasc Surg 1991;102:639-40.

14. Carrel T, Kujawski T, Zünd G, Schwitter J, Amann FW, Gallino A, et al. The internal mammary artery malperfusion syndrome: incidence, treatment and angiographic verification. Eur J Cardiothorac Surg 1985;9:190-7.

15. Carrel T, Zünd G, Schuiki E, Amann FW, Turina M. Treatment of internal mammary artery malperfusion syndrome by additional venous graft: early postoperative angiographic results. Coron Artery Dis 1994;5:455-8.

16. Orszulak TA. Are arterial grafts better of worse than applied physiology teaches? Ann Thorac Surg 1986;56:809-11.

17. Stone GW, Hartzler GO. Spontaneous reversible spasm in an internal mammary artery graft causing acute myocardial infarction. Am J Cardiol 1989;64:822-3. 
18. Lust RM, Zeri RS, Gane PA, Hopson JB, Sum YS, Otaki M, et al. Effect of chronic native flow competition on internal thoracic artery grafts. Ann Thorac Surg 1994;57:45-50.

19. Kitamura S, Kawachi K, Seki T, Sawabata N, Morita R, Kawata T. Angiographic demonstration of no-flow anatomic patency of internal thoracic-coronary artery bypass grafts. Ann Thorac Surg 1992;53:156-9.

20. Feld H, Navarro V, Kleeman H, Shani J. Early postoperative occlusion of a left internal mammary artery bypass graft with subsequent restoration of patency. Cathet Cardiovasc Diagn 1992;27:280-3.
21. Aris A, Borras X, Ramio J. Patency of internal mammary artery grafts in no-flow situations. J Thorac Cardiovasc Surg 1987;93:62-4.

22. Flemma RJ, Singh HM, Tector AJ, Lepley D Jr, Frazier BL. Comparative hemodynamic properties of vein and mammary artery in coronary bypass operation. Ann Thorac Surg 1975; 20:619.

23. Granke K, Van Meter CH, White CJ, Ochsner JL, Hollier LH. Myocardial ischemia caused by postoperative malfunction of a patent internal mammary coronary arterial graft. J Vasc Surg 1990;11:659-64. 